Received: $1-\mathrm{XII}-2020$

Accepted: $10-|| \mid-2021$

Published Online: 14-IV-2021

\section{In-Vitro Silanization of Dental Enamel to Prevent Demineralization}

\section{Silanización in vitro sobre esmalte dental para prevenir desmineralización}

José R. Gutiérrez-Camacho DDS, MSc ${ }^{1}$; Luis Alejandro Aguilera-Galavíz DDS, MSc, PhD²; G. Sánchez-Balderas DDS, MSc; ; Gabriela Palestino DDS, MSc, PhD4; Norma Verónica Zavala-Alonso DDS, MSc, PhD5; César Gaitán-Fonseca DDS, MSc, PhD 6

1. Estudiante de la Maestría en Ciencias Biomédicas, Área Ciencias de la Salud, Universidad Autónoma de Zacatecas "Francisco García Salinas", Mexico. https://orcid.org/0000-0002-3897-8106 2. Maestría en Ciencias Biomédicas, Área Ciencias de la Salud, Universidad Autónoma de Zacatecas "Francisco García Salinas", Mexico. https://orcid.org/0000-0002-1513-4971 3. Instituto de Física, Universidad Autónoma de San Luis Potosí, Mexico. https://orcid.org/0000-0002-9433-8920 4. Facultad de Ciencias Químicas, Universidad Autónoma de San Luis Potosí, Av. Manuel Nava No. 6, CP 78210 San Luis Potosí, S.L.P., Mexico. https://orcid.org/0000-0002-7535-9363

5. Laboratorio del Doctorado de Ciencias Odontológicas, Universidad Autónoma de San Luis Potosí, Mexico. https://orcid.org/0000-0001-6014-0994

6. Maestría en Ciencias Biomédicas, Área Ciencias de la Salud, Universidad Autónoma de Zacatecas "Francisco García Salinas", Mexico. https://orcid.org/0000-0001-6452-2578

Correspondence to: Dr. César Gaitán-Fonseca - cgaitan@uaz.edu.mx

ABSTRACT: Caries is a multifactorial disease that can negatively affect dental tissues through the demineralization process, which produces acids deriving from the metabolism of carbohydrates. Some strategies to prevent this process have been proposed, such as topical fluoride application, resin-based restorations, pit and fissures sealers, infiltrated resins, vaccines, mouthwashes, and several brushing techniques. To evaluate in vitro enamel hydrophobic modification as a method of prevention against demineralization. A descriptive and comparative study was carried out. Thirty premolars extracted for orthodontic reasons were obtained, encapsulated in epoxy resin, sectioned, and sanded to obtain specimens $3 \mathrm{~mm}$ in thickness. The samples were pretreated with $\mathrm{NaOCl}$ and EDTA, incubated with 1 and 4\% octadeyltrichlorosilane (OTS) or with 3 and $6 \%$ octadecyltriethoxysilane (TEOS) for $5 \mathrm{~min}$ and for $8 \mathrm{~h}$. Subsequently, the samples were immersed in citric acid for 2 months. The samples were analyzed by their contact angle, infrared spectroscopy, scanning electron microscopy, atomic and confocal force, before and after treatment in citric acid. The samples coated with 1 and $4 \%$ OTS for $5 \mathrm{~min}$ and $8 \mathrm{~h}$ kept the silanizing agent on their surface after 2 months in citric 
acid. The treatment with TEOS was only effective at $6 \%$ with a reaction time of $5 \mathrm{~min}$. The modification with 1 and 4\% OTS protects the surface of the tooth enamel from demineralization in acidic medium. The results indicate that treatment with 4\% OTS is effective from $5 \mathrm{~min}$, which makes it appropriate in clinical practice.

KEYWORDS: Caries; Silanization; Octadecyltrichlorosilane; Octadecyltriethoxysilane.

RESUMEN: Caries es una enfermedad multifactorial que destruye en tejido dental por la desmineralización de ácidos generados en el metabolismo de carbohidratos. Algunos métodos preventivos, como fluoruro, resinas, selladores de fosetas y fisuras, resinas infiltradas, vacunas, enjuagues bucales, y un sinfín de técnicas de cepillado, han sido empleadas. Evaluar in vitro la modificación hidrofoba del esmalte como método preventivo en contra de la desmineralización. Un estudio decriptivo y comparativo fue empleado. Se obtuvieron treinta premolares sanos extraidos por razones ortodónticas y encapsulados en resina epóxica, seccionados y pulidos hasta obtener especímenes de $3 \mathrm{~mm}$ de grosor. Las muestras fueron pretratadas con $\mathrm{NaOCl}$ y EDTA, incubadas en octadeciltriclosorilano (OTS) al 1 y $4 \%$ y octadeciltrietoxisilano (TEOS) 3 y $6 \%$ por 5 min y $8 \mathrm{~h}$. Después, las muestras fueron sumergidas en ácido cítrico por 2 meses. Las muestras fueron analizadas con ángulo de contacto, espectroscopía infrarroja, microscopía electrónica de barrido, atómica y confocal, antes y después de tratamiento con ácido cítrico. Las muestras cubiertas con OTS 1 y $4 \%$ por $5 \mathrm{~min}$ y 8 h mantuvieron el agente silanizante sobre la superficie después de 2 meses en ácido cítrico. El tratamiento con TEOS fue efectivo al 6\% y con un tiempo de reacción de 5 min. La modificación con 1 y $4 \%$ de OTS proteje la superficie del esmalte dental contra la desmineralización en un medio ácido. Estos resultados indican que el tratamiento con OTS $4 \%$ es efectivo desde $5 \mathrm{~min}$ de aplicación, lo cual es apropiado en la práctica clínica.

PALABRAS CLAVE: Caries; Silanización; Octadecitriclorsilano; Octadeciltrietoxisilano.

\section{INTRODUCTION}

Dental decay is a multifactorial disease that involves bacterial growth and a capacity to destroy a hard dental surface. The principal consequences are pain and demineralization at the enamel/ dentine interface. It is caused by the presence of acid products and the consequent carbohydrate metabolism in dental plaque (1-5).

Enamel is a hard tissue composed principally of hydroxyapatite crystals ( $\mathrm{Ca} 5(\mathrm{PO} 04) 3(\mathrm{OH}))$ assembling in rod and prism shapes at micrometer size. A hydrophilic characteristic is present due to a $10 \%$ water composition in porosities. On the other hand, when demineralization affects enamel, it induces a phenomenon of diffusion and substance exchanges, favoring decay, pain, and pulp damage (6). To prevent demineralization, some clinical strategies have been developed in enamel; principally the topical application of fluor, the sealing of prisms by resins, and modification of the hydrophobic surface (7-9).

A modification of the hydrophobic surface can involved different methods, of which silanization 
is an example. The goal is to chemically change the hydrophilic to the hydrophobic condition on the enamel's surface. To obtain this condition, a pretreatment protocol with EDTA and $\mathrm{NaOCl}$ is necessary for exposed collagens fibers and hydroxyapatite film (HA) for the silanization protocol (10). This strategy is employed with excellent results in dentistry, and in the textile, electronics, telephonic, construction, and in the food industries (11-13).

Currently, silanization is employed in endodontic and prosthetic processes; however, the goal is its possible use in preventive dentistry. For example and reciently Icon ${ }^{\circledR}$ (DMG America) is a dental material that act as infiltrators in spaces created in the demineralization process, it is a $15 \%$ hydrochloric acid gel that fills cavities, preserving healthy dental structures. It is not similar to silanization, but it is a recent clinical tactic in preventive dentistry that employs resin infiltration to prevent decay development (14).

In the literature, there are reports on the chemical modification of intra-radicular dentine by silanization with octadecyltrichlorosilane (OTS) and octadecyltrietoxisilane (TEOS). In these studies, it was demonstrated that the dentin surface acquired a better root seal on proceeding from a hydrophilic to a hydrophobic state after silanization with OTS $(15,16,18)$.

Patiño et al. developed a protector effect on hydroxyapatite (HA) film against acid erosion with silanization by OTS. These authors demonstrated the protector effect of a hydrophobic surface against acid erosion employing OTS on hydroxyapatite (HA) films and on dental samples in which no significant erosion was observed. These results validate that a hydrophobic surface can be an effective dental protector against acid erosion (10).
On the other hand, Reis et al. (17) evaluated dental composites and their capacity of enamel remineralizing containing silica-hydroxiapatite (Si-HAp) nanoporus particles charged with sodium fluoride (NaF). These authors mentioned that composites presented a remineralizing activity in human enamel and that this ability underwent a subtle reduction after particle silanization (17).

Therefore, the objective of this study was to evaluate the silanization of dental enamel using octadeyltrichlorosilane (OTS) and octadecyltriethoxysilane (TEOS) for the prevention and demineralization of dental enamel through by means of an ex-vivo assay.

\section{MATERIALS AND METHODS}

\section{BIOETHICAL CONSIDERATIONS}

This protocol was authorized by COFEPRIS with authorization number CI-UAE-15-2020.

\section{SAMPLE COLLECTION}

Thirty premolars extracted for orthodontic reasons were collected at the Multidisciplinary Clinic of the Master of Biomedical Sciences Program of the Autonomous University of Zacatecas (CLIMACB) and were stored for 2 weeks in distilled water until the procedure with the different materials. To obtain a flat enamel surface, the teeth were fragmented and mounted in epoxy resin. After a sixty-four samples (square, $5 \times 5 \mathrm{~mm}$ ) were sanded until the concave enamel was removed and specimens $3 \mathrm{~mm}$ in thickness were obtained. Later, these were recovered from the epoxy resin and cutted with a high speed motor (RAY-FOSTER, USA), burn 701 (DENTSPLY, SIRONA, USA), and carbide disc (DENTSPLY, SIRONA, USA). Afterward, in an optic microscope (MICROVISION, USA), the samples 
were evaluated to rule out the presence of epoxyresin residues.

\section{PRETREATMENT}

All samples were immersed in $17 \%$ EDTA (3min), 2.5\% NaOCl (5min), 17\% EDTA (3min), and finally, were rinsed in deionized water. The aim of this protocol was to expose the collagen fibers and the HA indispensable for developing Si-O bonds in this silanization protocol (Figure 1) $(16,10)$.

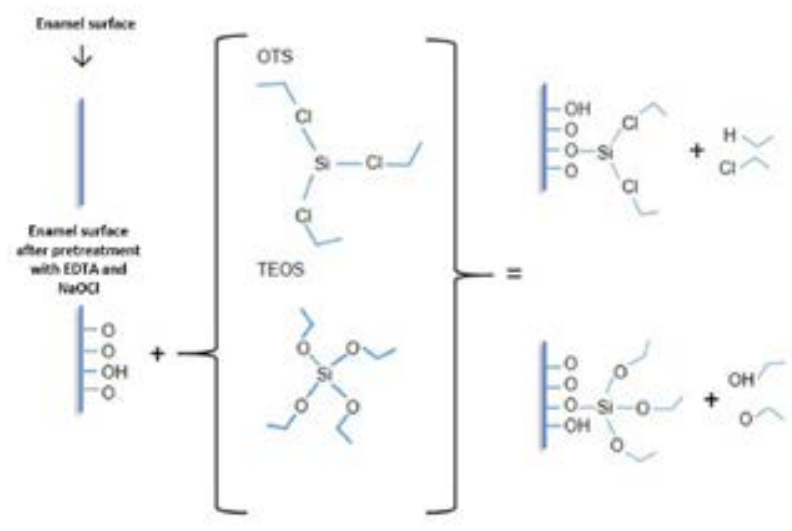

Figure 1. Schematic representation of silanization in dental enamel. In the schema, a pretreatment protocol and silanization were observed, On the left, a raw enamel surface raw is pretreated with EDTA and $\mathrm{NaOCl}$ for exposed collagen fibers and $\mathrm{HA}$ in enamel. After a silanization protocol, OTS and TEOS were developed. Finally, covalent bonds between $\mathrm{Si}-0$ are developed in enamel and indicated a hydrophobic surface.

\section{SILANIZATION PROTOCOL}

\section{OTS SILANIZATION}

Two different storage solutions were prepared for the silanization process: solution 1: OTS $1 \%$ (10 ml ethyl acetate $+100 \mu \mathrm{L}$ OTS), and solution 2, 0TS 4\% (10 ml ethyl acetate $+400 \mu \mathrm{L}$ OTS). The enamel fragments were divided into the following eight groups ( $\mathrm{n}=4$ per group): [OTS $1 \%$ $+5 \mathrm{~min} ;$ OTS $1 \%+8 \mathrm{~h}$; OTS $1 \%+5 \mathrm{~min}+60$ days in citric acid; OTS $1 \%+8 \mathrm{~h}+60$ days in citric acid; OTS $4 \%+5 \mathrm{~min}$; OTS $4 \%+8 \mathrm{~h}$; OTS $4 \%$ $+5 \min +60$ days in citric acid, and OTS $4 \%+$ $8 \mathrm{~h}+60$ days in citric acid]. These were randomly distributed and silanizated for $5 \mathrm{~min}$ and for $8 \mathrm{~h}$, respectively $(10,16)$.

\section{TEOS SILANIZATION}

In the same manner, storage solution 1 , consisting of TEOS $3 \%(300 \mu \mathrm{L}$ TEOS $+10 \mathrm{ml}$ ethanol $+200 \mu \mathrm{L}$ acetic acid), and storage solution 2 , consisting of TEOS $6 \%(600 \mu \mathrm{L}$ TEOS $+10 \mathrm{ml}$ ethanol $+200 \mu \mathrm{L}$ acetic acid) were prepared. Another eight groups ( $\mathrm{n}=4$ per group), including [TEOS 3\% + 5min, TEOS 3\% + 5min + 60 days in citric acid, TEOS $3 \%+8 h$, TEOS $3 \%+8 h+$ 60 days in citric acid, TEOS $6 \%+5 \min$, TEOS $6 \%$ $+5 \mathrm{~min}+60$ days in citric acid, TEOS $6 \%+8 \mathrm{~h}$, and TEOS $6 \%+8 \mathrm{~h}+60$ days in citric acid] were silanized for 5 min and for $8 \mathrm{~h}(10,16)$.

On finalizing the silanization protocols, the groups were evaluated in terms of Contact Angle, Atomic Force Microscopy, Scanning Electronic Microscope, and Fourier Transformed Infrared Spectroscopy.

\section{CONTACT ANGLE (CA)}

Ten- $\mathrm{LL}$ drops of water were randomly disposed on different silanized enamel zones and contact angle (CA) measurements were developed in a Goniometer (DIGIDROP, FRANCE) at room temperature 10 times.

\section{FOURIER TRANSFORMED INFRARED SPECTROSCOPY (FTIR)}

An FTIR evaluation was made in a spectrophotometer Nicolet Nexus 470 FTIR Spectrophotometer (NICOLET, MADISON, WI, USA). The bonds $\mathrm{PO}_{4}{ }^{3-}, \mathrm{OH}^{-}, \mathrm{C}-\mathrm{Cl}, \mathrm{Si}(\mathrm{CH})_{3}, \mathrm{Si}-\mathrm{OH}$, and 
Si-0-Si were analyzed on silanized surfaces. All samples and control were analyzed at wavenumber $3,000-500 \mathrm{~cm}^{-1}$.

\section{SCANNING ELECTRONIC MICROSCOPY (SEM)}

A microscope (JSM-6510; JEOL, JAPAN) was employed at 550X magnification. In all samples, EDX analyses were processed. The samples were dried in alcohol at different concentrations and then dried in an oven for their coating with gold and their analysis.

\section{ATOMIC FORCE MICROSCOPY (AFM)}

An Atomic Force Microscope (AFM) (Bruker, Dimension Edge model, USA) was utilized to evaluate the morphology and roughness of the silanized surfaces before and after remaining in citric acid on a $20-\mu \mathrm{m} \times 20-\mu \mathrm{m}$ surface; the quadratic Roughness $(\mathrm{Rq})$ of each specimen was obtained.

\section{CONFOCAL MICROSCOPY (CM)}

Some complete premolars dental organs were pretreated as described previously. The coating solution with $1 \%$ and $4 \%$ OTS, or with $3 \%$ and $6 \%$ TEOS, was mixed with the compound Rhodamine (Sigma-Aldrich, 99\% pure) to obtain a final concentration of $20 \mu \mathrm{g} / \mathrm{ml}$. Subsequently, the pieces were varnished in enamel with the solution containing the silanizing agent and the Rhodamine; subsequently, the dental organs were immersed in citric acid for 8h. After 8h, the pieces were sectioned (square, $5 \times 5 \mathrm{~mm}$ ) with an isometric seal (CIENTEC) for their subsequent analysis in enamel by Laser Confocal Microscopy (LCM).

\section{RESULTS}

\section{CONTACT ANGLE (CA)}

Figure 2 presents the averages of the CA measurement. Under a black bar, samples presenting less than 90 degrees are considered hydrophilic surface, and above the bar, we find all silanized specimens with a CA of more than 90 degrees are a hydrophobic surface. Specimens coated with $4 \%$ OTS for $8 \mathrm{~h}$, exhibited the highest average CA measurement $\left(>130^{\circ}\right)$, while those silanized with $3 \%$ TEOS for 5 min had the lowest average CA $\left(<75^{\circ}\right)$.

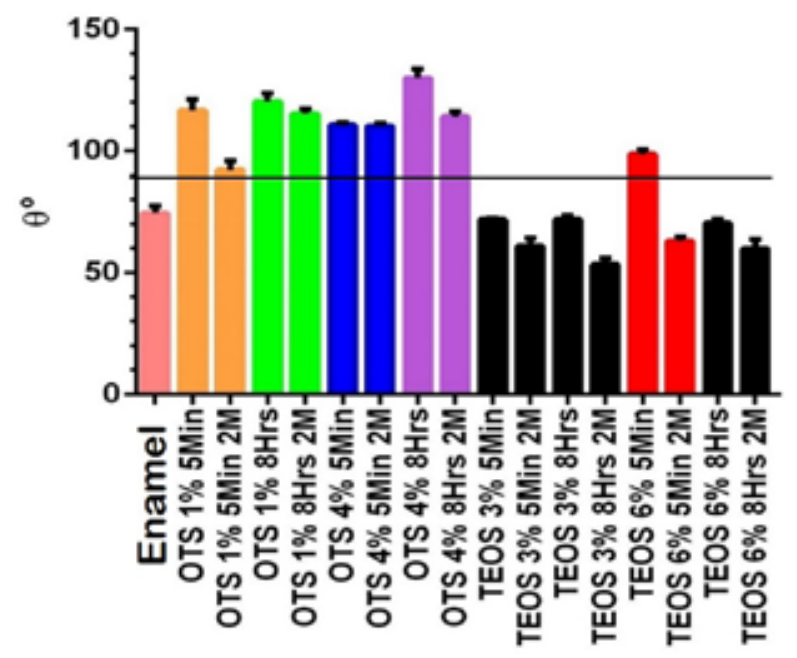

Figure 2. Contact angle measurements. Average of samples in the contact angle. Enamel was control without pretreatment and all silanized groups were measured. The test was conducted immediately and after 2 months in citric acid in all groups. The groups above the black bar (>90 degrees) are considered a hydrophobic surface.

\section{FOURIER TRANSFORMED INFRARED SPECTROSCOPY (FTIR)}

In Figure 3, a control (enamel) presents characteristic bonds $(3,200 \mathrm{~cm}-1)$ of the elements 
in hydroxyapatite $(\mathrm{P}-\mathrm{OH}, \mathrm{OH})$. These bonds are indispensable in the silanization process. In silanized groups, there are present the characteristic bands of $\mathrm{Si}-\mathrm{OH}(3,200 \mathrm{~cm}-1)$ and $\mathrm{Si}-0-\mathrm{Si}(1,500-750$ $\mathrm{cm}-1$ ), in contrast with the CA frequency of $\mathrm{Si}-0-\mathrm{Si}$ and $\mathrm{Si}-\mathrm{OH}$ bands. The samples expressed that certain elements can be variable depending on the percentage of silica on the modified surface.
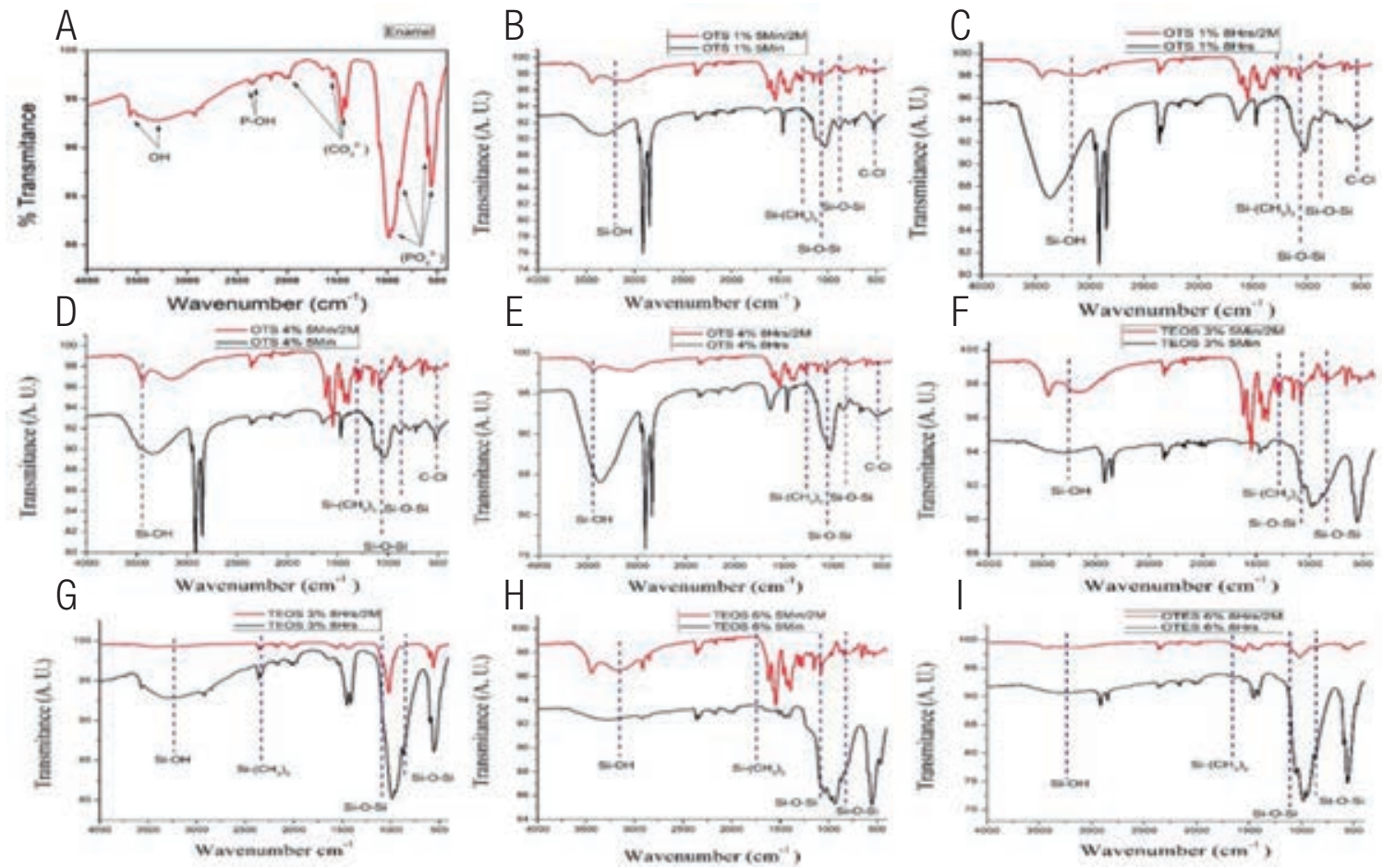

Figure 3. FTIR spectra. The FTIR enamel spectrum (A) has shown the characteristic bands of hydroxyapatite. The FTIR spectra of the specimens coated with OTS at $1 \%$ for $5 \mathrm{~min}(\mathrm{~B})$, OTS at $1 \%$ for $8 \mathrm{~h},(\mathrm{C}), 0 \mathrm{TS}$ at $4 \%$ for $5 \mathrm{~min}$ (D), and OTS at $4 \%$ for $8 \mathrm{~h}$ (E), those coated with TEOS at $3 \%$ for $5 \mathrm{~min}(\mathrm{~F})$, and at $3 \%$ for $8 \mathrm{~h}(\mathrm{G})$, while TEOS at $6 \%$ for $5 \mathrm{~min}(\mathrm{~h}), 6 \%$ for $8 \mathrm{~h}(\mathrm{I})$ are shown in the histograms in black bands, compared with the spectra of the same samples after remaining in citric acid for 60 days. The comparative bands are shown in red.

\section{SCANNING ELECTRONIC MICROSCOPY (SEM)}

In the SEM analysis, Figure $4 \mathrm{~A}$ represents enamel without silanization. Images $4 \mathrm{~B}-4 \mathrm{Q}$ represent all groups silanized with OTS and TEOS. In each image, a Si percentage was determined with EDX analysis.

\section{ATOMIC FORCE MICROSCOPY (AFM)}

Figure 5 shows the histograms of the groups roughness and topography. The enamel presents a surface that is uniform and smooth. Other histograms represent that were silanized and left in citric acid after 60 days. The TEOS groups possess minor modifications after their remaining in the citric acid. The average $\mathrm{Rq}$ obtained with silanization was $1.0849 \mu \mathrm{m}$ and, after being in citric acid, the Rq was $2.486 \mu \mathrm{m}$.

\section{CONFOCAL MICROSCOPY LASER SCANNING (CMLS)}

In the microphotographs (Figure 6) of OTS and TEOS coating with Rhodamine, the silanizing agents are observed as red in color on the surface of the dental enamel. This indirect marking allows us to observe the homogeneity and continuity of the silanizing coating, as well as whether it possesses fractures or partial or total loss of the coating after remain in the citric acid. 

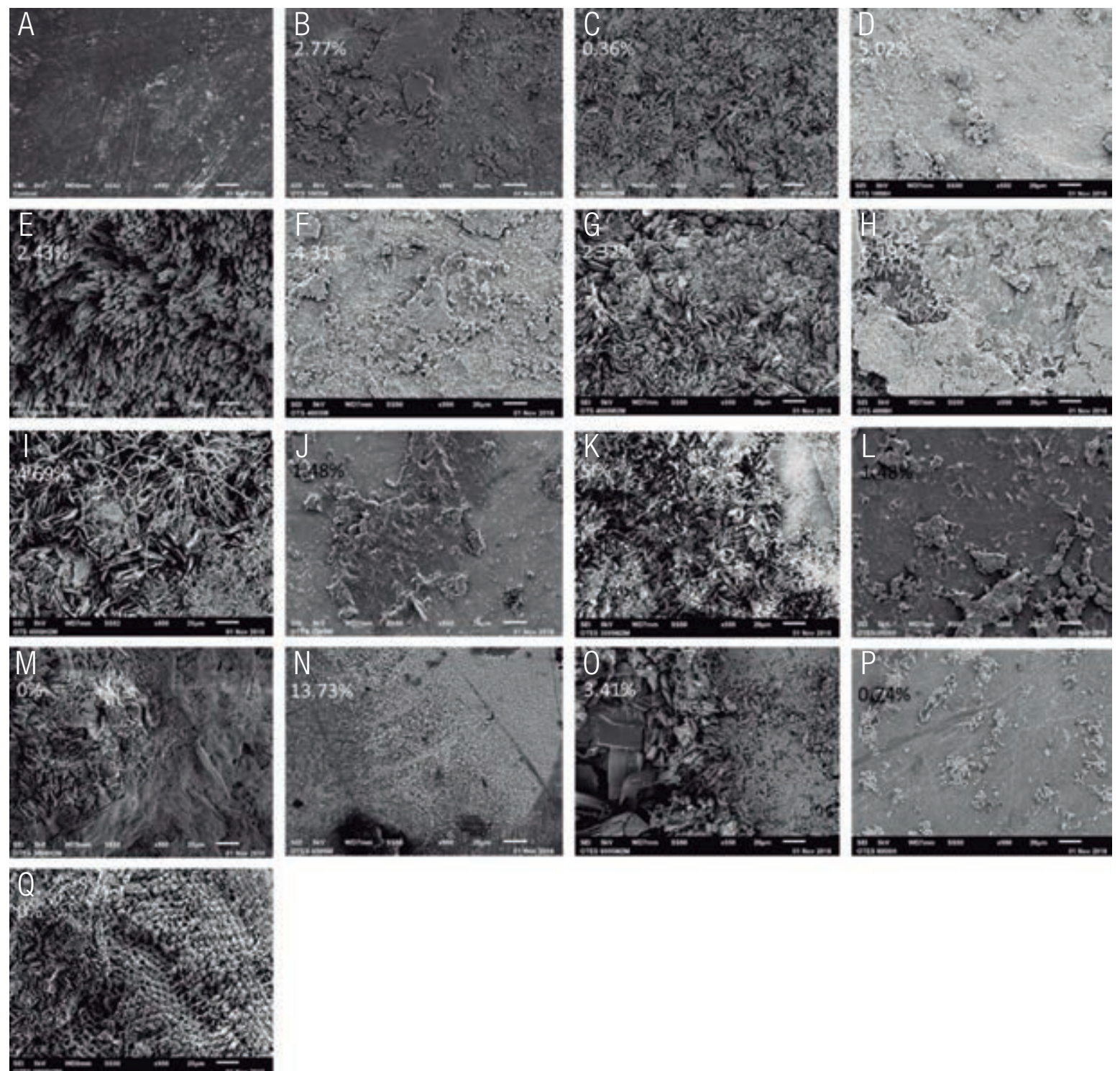

Figure 4. Scanning Electronic Microscopy analysis. SEM images showing analyzed the surface morphology and percentage of Si, (A), enamel, (B), $1 \%$ OTS $+5 \mathrm{~min}$, (D), $1 \%$ OTS $+8 \mathrm{~h},(\mathrm{~F}), 4 \% \mathrm{OTS}+5 \mathrm{~min}$, and $(\mathrm{H}), 4 \%$ OTS $+8 \mathrm{~h}$, and the silanized surfaces: (J), with 3\% TEOS + 5min, (L), 3\% TEOS + 8h, (N), 6\% TEOS + 5min, and (P). 6\% TEOS + 8h. After immersion in citric acid for 60 days: (C), $1 \%$ OTS + 5min, (E). 1\% OTS + 8h, (G). 4\% OTS + 5min, (I), 4\% OTS + 8h, (K), 3\% TEOS + 5min, (M), 3\% TEOS + 8, (0), 4\% TEOS + 5min, and (Q), 4\% TEOS + 8h. 

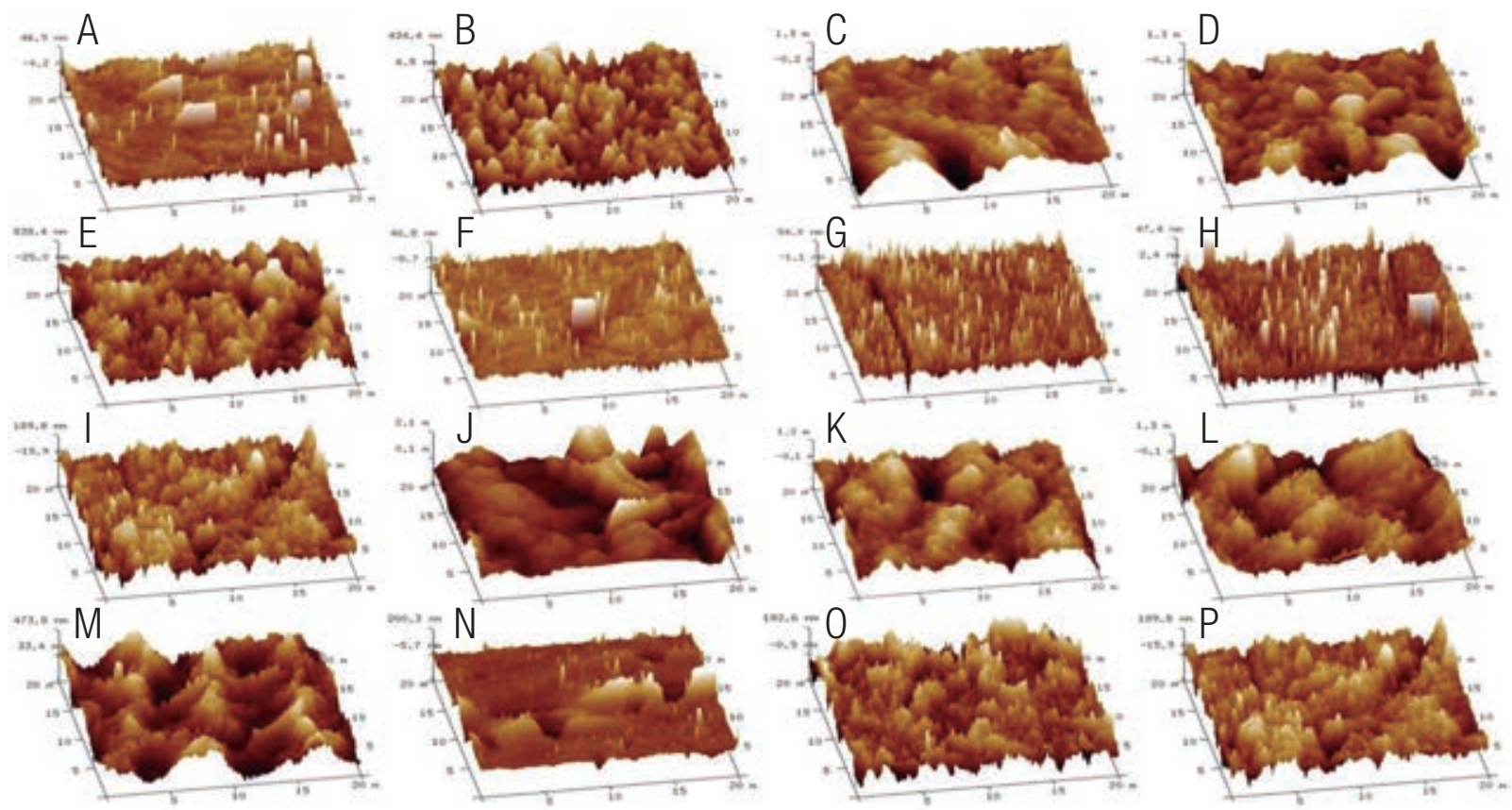

Figure 5. Atomic Force Microscopy (AFM) evaluation. AFM images showing the morphology of the surfaces of the specimens analyzed, depicting the morphology enamel (A), to the surface of the specimens silanized with 1\% OTS + 5min (B), 1\% 0TS + 8h (D), 4\% 0TS + $5 \mathrm{~min},(\mathrm{~F}), 4 \%$ OTS + 8h, and (H) with 3\% TEOS + 5min (J), 3\% TEOS + 8h (L), 6\% TEOS + 5min (N),6\% TEOS + 8h (P). The topography of the silanized specimens is also shown after they have been immersed in citric acid for 60 days, with $1 \%$ OTS $+5 \mathrm{~min}(\mathrm{C}), 1 \%$ 0TS $+8 \mathrm{~h}$ (E), 4\% OTS + 5min (G), 4\% OTS + 8h (I), 3\% TEOS + 5min (K), 3\% TEOS + 8h, and (M), 6\% TEOS + 5min.

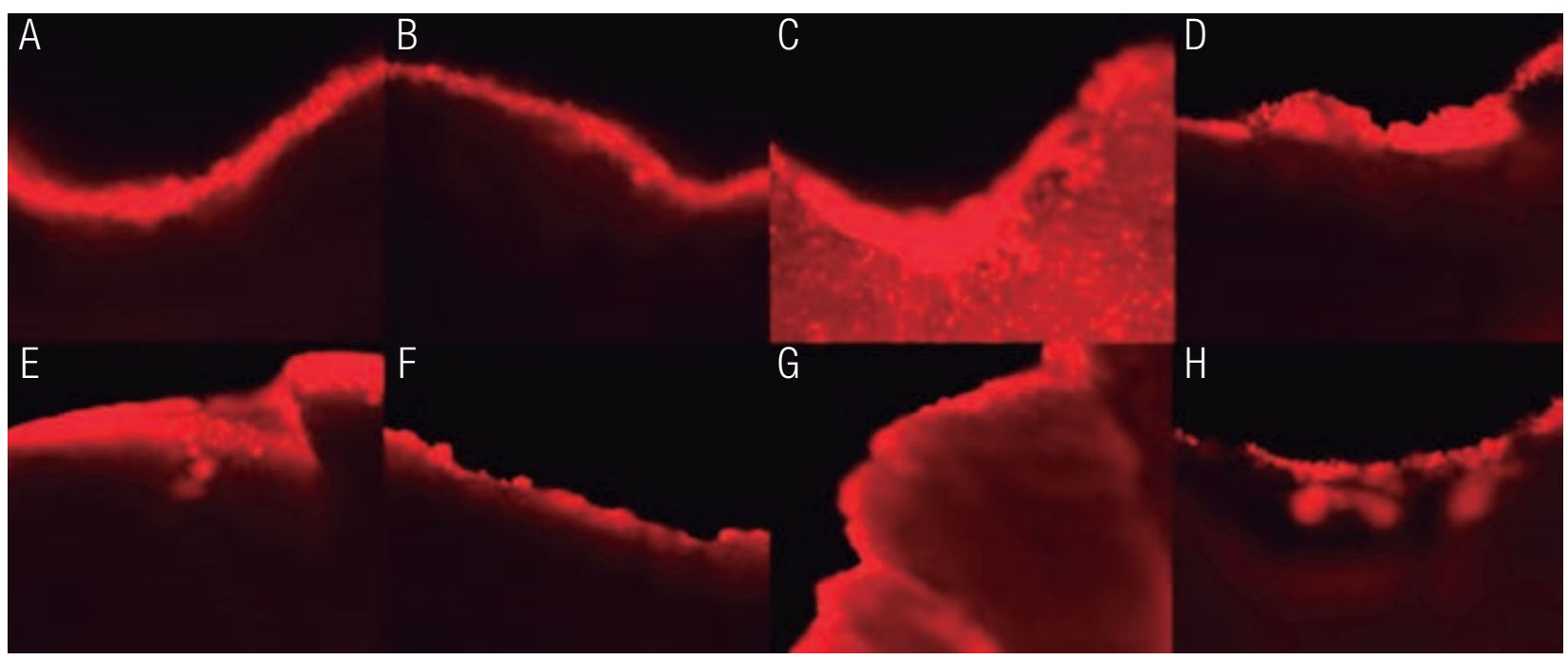

Figure 6. Confocal Microscopy analysis. Confocal microscope images of the surface of the dental organs varnished with 1\% and $4 \%$ OTS stained with Rhodamine ( $\mathrm{A}$ and $\mathrm{C}$ ) and with $3 \%$ and $6 \%$ TEOS stained with Rhodamine (E and G). Images of the same specimens coated with $1 \%$ and $4 \%$ OTS stained with Rhodamine (B and D) and with $3 \%$ and $6 \%$ TEOS stained with Rhodamine ( $F$ and $H)$ after being in an acidic medium for $8 \mathrm{~h}$. 


\section{DISCUSSION}

The results obtained in the measurement of the contact angle showed a hydrophilic enamel ( $<90$ degrees), this being a surface control prior to the silanization process. In the investigation carried out by Collart and collaborators in 2013 on the salinization of dentine in root canals, the authors obtained results in which the contact angle is longer than 70 degrees. The same results were obtained after the surface of the tooth enamel was silanized with Octadecyltrichlorosilane and Octadecyltriethoxysilane. In all of the surfaces coated with OTS, the contract angle was measured immediately afterward and the latter were at an angle greater than 90 degrees, indicating that the surface had undergone a modification from hydrophilic to hydrophobic. These surfaces maintained contact angles higher than 90 degrees after having been subjected to citric acid for 2 months $(10,11,18)$.

The TEOS-coated surfaces coated with concentration of $6 \%$ and silanized for $5 \mathrm{~min}$, had a contact angle measurement higher than 90 degrees. Nevertheless, when measuring of the contact angle was performed after these samples had been in citric acid for 2 months, the measurements effected rendered angles smaller than 90 degrees. In this regard, our results coincide with those of Patiño-Herrera, in which these authors synthesize hydroxyapatite and fluorapatite in gold sensors. In this research, these compounds were coated with OTS and then, several analyzes were conducted. These results were very important for this project $(15,16)$.

The results discussed previously were not sufficient to guarantee that the tooth enamel surface was coated with OTS or TEOS. Thus, it was necessary to perform an infrared spectroscopy (FTIR) analysis, in order to verify the presence of the bonds and functional groups-of-interest that guarantee the bonding of the silanizing agent with the surface of the dental enamel. The peaks and curves that are observed at different wave numbers in the different spectra correspond to those obtained by Patiño et al., in their research in 2015 and by Collart in 2013. According to the results obtained, the silicon in the silanizing agents is bound by a covalent bond to oxygen on the surface of tooth enamel. It is noteworthy that the chemical bond between the previously mentioned elements is the strongest that exists in nature, in addition to being the most abundant element in the earth's crust $(10,15,16)$.

Scanning electron microscopy (SEM) was another essential analysis that was performed to ensure the existence of a coating on the tooth enamel. In this analysis, we also observed the topography of dental enamel itself, of the dental specimens recently coated with OTS and TEOS, and of the dental specimens coated with OTS and TEOS after having remained in citric acid for 2 months. In the images of the newly silanized specimens obtained in the present investigation and in that carried out in 2015 by Patiño and collaborators, we find great similarity with the images obtained from the specimens that had been subjected to citric acid. In the investigations, this image presents a less irregular surface than those we obtained, probably because these authors subjected only the silanized specimens to the demineralization process for $168 \mathrm{~h}$ and, in the present investigation, these remained for 1,440h, that is, of 2 months. In the EDS or EDX (energydispersive X-ray spectroscopy) analysis was conducted to determine the percentage elements constituted the surface of the analyzed specimen, as carried out in later investigations $(10,16,18)$.

One of the analyses employed to observe the surface topography of the dental enamel was Atomic Force Microscopy (AFM). In the investigation carried out by Patiño and collaborators in 2015, the aithors applied only this analysis to the hydroxyapatite and fluorapatite, and they 
synthesized and deposited the dental enamel on gold sensors; We thought it necessary to perform this analysis on fresh specimens coated with OTS and TEOS and after exposing them to citric acid for 2 months, in order to verify that the structure of the silanizing agent remained after exposure to acid. In order to have an objective result, it was necessary to obtain the quadratic roughness and the histograms of the number of frequency of the measurements procured on conducting this analysis. This indicated that, as there is less variation in the results of the histograms and that in the quadratic roughness, there is a similar or equal presence of the silanizing agent before and after the specimens were exposed to citric acid (10).

Marzuki et al., on using confocal laser microscopy (CLSM), obtained images of the dentin structure utilizing Rhodamine as a stain, in which they observed structural and mineral changes in the carious dentin (19). In our results, the specimens coated with OTS are those in which a more homogeneous coating of the tooth enamel is observed.

\section{CONCLUSIONS}

We analyzed specimens of the surface of tooth enamel coated with OTS and TEOS; there were fresh specimens that were exposed to citric acid for 2 months. Silanization with $4 \%$ and $1 \%$ OTS with a silanization time of 5 min and 8 creates a hydrophobic protective layer that remains nearly unchanged in terms of the Si percentage even after exposure to citric acid.

Therefore, we conclude that, by forming a hydrophobic layer on the surface of tooth enamel with OTS, the latter will provide a protective layer that will prevent demineralization in an acidic environment.

\section{REFERENCES}

1. Norma Oficial Mexicana NOM-013SSA2-2015, Para la prevención y control de enfermedades bucales.

2. Lihong G., Wenguan S. Salivary biomarker for caries risk assessment. J Calif Dent Assoc. 2013; 41 (2): 107-108.

3. Alaa M., Anette C., Guglielmo C., Peter L. Supragingival plaque microbial analysis in reflection to caries experience. BMC Oral Health. 2013;13:5. DOI: 10.1186/1472-683113-5

4. V. W.M., James K.H., Janice S.B., Carlos G.C., Judith R.C., George J.E., et al. Total IgA and IgA reactivity to antigen I/II epitopes in HLA-DRB1*04 positive subjects. Open J Immunol. 2013; 3 (3): 82-92. DOI: 10.4236/ oji.2013.33012

5. Negori M. Microbiología Estomatológica, Fundamentos y Guía Práctica, Buenos Aires, Argentina: Editorial Médica Panamericana; 2012.

6. Jing X., Z. R.T., Licheng H., Lei C., Zhongrong Z., Linmao Q., et al. Enamel crystallite strength and wear: nanoscale responses of teeth to chewing loads. J R Soc Interface. 2017; 14 (135): 20170456. DOI: 10.1098/rsif.2017.0456

7. Nedeljkovic I., Teughels W., De Munck J., Bart V.M., Kirsten L.V.L. Is secondary caries with composites a material-based problem? Dent Mater. 2015; 31 (11): e247-e277. DOI: 10.1016/j.dental.2015.09.001

8. Cury J.A., de Oliveira B.H., dos Santos A.P., Tenuta L.M. Are fluoride releasing 
dental materials clinically effective on caries control?. Dent Mater. 2016 Mar; 32 (3): 323-233. DOI: 10.1016/j.dental.2015.12.002

9. Shanmugam K.T., Masthan K.M.K., Balachander N., Sudha Jimson, Sarangarajan R. Dental caries vaccine - a possible option? J Clin Diagn Res. 2013; 7 (6): 1250-1253. DOI: $10.7860 / J C D R / 2013 / 5246.3053$

10. Patiño H.R., González A.G., Estrada B.A., Escoto C.S.E., Pérez E. Hydrophobic coatings for prevention of dental enamel erosion. Surf Coat Technol. 2015; 275: 148-154. DOI. org/10.1016/j.surfcoat.2015.05.026

11. Bordenave N., Grenier S., Coma V. Hydrophobization and antimicrobial activity of chitosan and paper-based packaging material. Biomacromolecules. 2010; 11 (1): 88-96. DOI: $10.1021 / \mathrm{bm} 9009528$

12. Hoefnagels H.F., Wu D., With G., Ming W. Biomimetic superhydrophobic and highly oleophobic cotton textiles. Langmuir 2007: 23 (26):13158-13163. DOI: 10.1021/la702174x

13. Kabanov A.V., Batrakova E.V. New technologies for drug delivery across the blood brain barrier. Curr Pharm Des. 2004; 10 (12): 1355-1363.

14. Sandoval P., Vogel R., Henríquez D., Knösel M. Management of post-orthodontic whitespot-lesions: Clinical handling of the resin infiltration technique (Icon $\mathbb{R}, \mathrm{DMG})$. Int $\mathrm{J}$
Odontostomat. 2016; 10 (1): 29-33. DOI: org/10.4067/S0718-381X2016000100006

15. Patiño H.R., Morales R.J., Gaitán F.C., Cuisinier F., Pérez E. Intraradicular dentine silanization by anew silicon-based endodontic sealer. Int J Adhes Adhes. 2016;69:115-124. DOI: org/10.1016/j.ijadhadh.2016.03.013

16. Collart D.P., Gaitán F.C., Zimanyi L., Romieu O., Pozos G.A., Semetey V., et al. Root canal hydrophobization by dentinal silanization: Improvement of silicon-based endodontic treatment tightness. Int $\mathrm{J}$ Adhes Adhes. 2013;101:721-728. DOI: 10.1002/jbm.b.32874

17. Reis D.P., Filho J.D.N., Rossi A.L., de Almeida Neves A, Portela MB, da Silva EM. Remineralizing potential of dental composites containing silanized silica-hydroxyapatite (Si-HAp) nanoporous particles charged with sodium fluoride (NaF). J Dent. 2019 Nov; 90: 103211. DOI: 10.1016/j.jdent.2019.103211

18. Gaitán F.C., Collart D.P., Semetey V., Romieu O., Cruz R., Flores H., et al. Chemical treatment of the intra-canal dentin surface: a new approach to modify dentin hydrophobicity. J Appl Oral Sci. 2013; 21 (1): 63-67. DOI: 10.1590/1678-7757201302168

19. Marzuki A.F., Masudi S.M. Confocal laser scanning microscopy study of dentinal tubules in dental caries stained with alizarin red. Arch Orofac Sci. 2008; 3 (1): 2-6. 